\title{
NOVAS ESPÉCIES DE ACROSTERNUM SUBGÊNERO CHINAVIA (HETEROPTERA, PENTATOMIDAE, PENTATOMINI) ${ }^{1}$
}

\author{
Angélica Frey-da-Silva ${ }^{2}$ \\ Jocélia Grazia ${ }^{2}$
}

\begin{abstract}
NEW SPECIES OF ACROSTERNUM SUBGENUS CHINAVIA (HETEROPTERA, PENTATOMIDAE, PENTATOMINI). Four new species of Acrosternum from Brazil are described: Acrosternum (Chinavia) immaculatum (Pará, Mato Grosso, Minas Gerais), A. (C.) panizzii (Paraná), A. (C.) pontagrossensis (Paraná) and $A$. $(C$.) rideri (Amazonas, Mato Grosso, Goiás, Distrito Federal, Minas Gerais). The external and internal genitalia of both sexes, except of $A$. $(C$.) pontagrossensis are studied. A key for the identification of all known species of the genus is included.
\end{abstract}

KEYWORDS. Heteroptera, Pentatomidae, Acrosternum, Chinavia, Taxonomy.

\section{INTRODUÇÃO}

O gênero Acrosternum foi proposto por FIEBER (1860) para única espécie, Acrosternum heegeri. ORIAN (1965) propôs o gênero Chinavia, que incluía algumas espécies antes pertencentes ao gênero Acrosternum. LinNavouri (1972) sinonimizou Chinavia e Acrosternum. Rolston (1983) afirmou que Chinavia é um grupo válido como um subgênero de Acrosternum, e incluiu neste todas as espécies americanas e as 9 espécies de Chinavia sensu Orian, da África, Madagascar e Ilhas Maurício. Até o momento o subgênero conta com 56 espécies, sendo 23 destas descritas por RoLSTON (1983); estas espécies têm distribuição desde o Canadá no norte até a Patagônia no sul.

\footnotetext{
1. Dissertação de Bacharelado em Ciências Biológicas. Contribuição nº 356 do Departamento de Zoologia (UFRGS).

2. Departamento de Zoologia, Instituto de Biociências, Universidade Federal do Rio Grande do Sul (UFRGS), Av. Paulo Gama s/nº, CEP $90046-900$, Porto Alegre, RS, Brasil (Bolsista CNPq).
} 
O subgênero Chinavia caracteriza-se pelo espinho do terceiro segmento abdominal com comprimento variado; rostro geralmente terminando entre as metacoxas; carena mesosternal baixa, larga e evanescente posteriormente; metasterno elevado ou levemente convexo; bordo ventral do pigóforo projetado e curvado dorsalmente; capsula seminalis arredondada e com dois dentes.

Este subgênero, bem representado no Brasil, tem importância sob o ponto de vista econômico. Várias espécies são hóspedes de plantas cultivadas, por exemplo: $A$. $(C$.) impicticorne (Stål, 1872) (algodoeiro) e $A$. (C.) bellum Rolston, 1983 (soja) (Silva et al., 1968; VeCCHIO et al., 1988).

Em amostras de pentatomídeos enviados para identificação ao Setor de Entomologia Sistemática, localizamos exemplares de Acrosternum pertencentes a quatro novas espécies, as quais são aqui descritas.

\section{MATERIAL E MÉTODOS}

O material pertence às coleções: DARC (coleção particular de David A. Rider, Fargo, North Dakota), UFRG (Departamento de Zoologia, Universidade Federal do Rio Grande do Sul, Porto Alegre, RS), MNRJ (Museu Nacional, Universidade Federal do Rio de Janeiro, Rio de Janeiro, RJ), DZUP (Departamento de Zoologia, Universidade Federal do Paraná, Curitiba, PR), CNPS (Centro Nacional de Pesquisa da Soja, Empresa Brasileira de Pesquisa Agropecuária, Londrina, PR) e INPA (Instituto Nacional de Pesquisas da Amazônia, Manaus, AM).

As medidas são apresentadas em milímetros correspondendo à média e aos valores mínimos e máximos. Os parâmetros morfométricos utilizados são: comprimento e largura da cabeça; distância interocular; comprimento adiante dos olhos; comprimento dos segmentos antenais I, II, III, IV e V; comprimento e largura (ao nível dos úmeros) do pronoto; comprimento e largura do escutelo; largura do abdome (ao nível do ápice do 3 ํㅗe segmento do conexivo) e comprimento total do corpo (do ápice do clípeo até o ângulo apical do 7o segmento do conexivo). A terminologia adotada para as peças da genitália segue Dupuss (1970).

Chave das espécies de Acrosternum (Chinavia) modificada de Rolston (1983).

1. Ângulos umerais formando angulos ou espinhos, desenvolvidos lateralmente, além do cório, por mais do que a metade da largura de um olho ............. 4 Ângulos umerais não formando espinhos, geralmente arredondados ou em ângulo que não alcança a metade da largura de um olho ........................ 2

2(1). Espinho abdominal projetando-se além do limite anterior das metacoxas .... 6 Espinho abdominal ou tubérculo não ultrapassando as metacoxas ............... 3

3(2). Metade lateral ou mais da sutura transversal do conexivo (toda sutura, não somente a parte exposta se ela estiver parcialmente coberta) bordeada de negro em um ou ambos lados.( RoLston, 1983, fig. 26) ........................ 47

Conexivo imaculado ou com mancha, ou mácula negra, nos ângulos pósterolaterais dos segmentos (Rolston, 1983, figs. 33, 34, 40) ....................... 18

4(1). Espinho abdominal projetando-se um pouco além do limite anterior das mesocoxas; sutura transversal do conexivo bordeada de negro em ambos os lados ................................................................. ( C.) insulani Rolston

Espinho abdominal não ultrapassando as metacoxas; conexivo com pequena mancha negra nos ângulos póstero-laterais dos segmentos ....................... 5

5(4). Margem lateral da cabeça, anteriormente aos olhos, afilando-se abruptamente até o estreito ápice da cabeça; pigóforo moderadamente emarginado em vista posterior A. (C.) bellum Rolston 
Cabeça menos afilada, ápice moderadamente arredondado; pigóforo profundamente emarginado em vista caudal ............. (C.) armigerum Stål

6(2). Ruga ostiolar não muito mais longa do que o ostíolo . A. (C.) abnorme (Berg) Ruga ostiolar alcançando a metade ou mais da distância do ostíolo até a margem

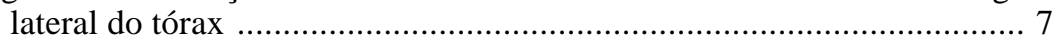

7(6). Segmentos do conexivo com a margem posterior bordeada de negro........... 8 Segmentos do conexivo com mácula grande negra, cada uma dividida por suturas transversais, ou com pequenos pontos negros nos ângulos póstero-laterais de cada segmento, ou ainda imaculados

8(7). Espinho abdominal apenas ultrapassando as metacoxas A. (C.) herbidum (Stål) Espinho abdominal atingindo ou ultrapassando a margem posterior das mesocoxas

9(8). Esternitos abdominais com pequenos calos, em ambos os lados da sutura transversal e pseudo-suturas A. (C.) callosum Rolston Esternitos abdominais desprovidos de calos ................ (C.) occultum Rolston

10(7). Espinho abdominal projetando-se além das mesocoxas ............................. 11 Espinho abdominal não se estendendo além da margem anterior das mesocoxas

11(10). Margens laterais das jugas negras, submarginadas com banda amarelada ....... A. (C.) sparnium (Dallas) Margens laterais das jugas não ou finamente delineadas de negro, submarginadas de verde ou verde-amarelado 61

12(10). Conexivo com manchas grandes, cada uma dividida por suturas transversais A. (C.) scutellatum (Dallas) Apenas os ângulos póstero-laterais dos segmentos dos conexivos negros ... 13

13(12). Espinho abdominal cônico, arredondado em secção transversal A. (C.) froeschneri Rolston

Espinho abdominal comprimido, não arredondado em secção transversal.. 14

14(13). Margem distal de cada cório de contorno parabólico, avançando sobre a membrana; espinho abdominal atingindo o limite anterior das mesocoxas (RoLston, 1983, fig. 58) ............................ A. (C.) longicorialis (Breddin)

Margem distal de cada cório sub-retilíneo, não avançando sobre a membrana; espinho abdominal terminando próximo ao limite posterior das mesocoxas (Rolston, 1983, fig. 57)

15(14). Margens laterais das jugas levemente côncavas adiante dos olhos (RoLston, 1983, fig. 43) 16

Margens laterais das jugas claramente côncavas adiante dos olhos (RoLsTON, 1983, figs 50, 52)

16(15). Manchas negras do conexivo limitadas aos esternitos junto aos ângulos pósterolaterais; borda dorsal do corpo fraca ou incompletamente amarela

A. (C.) esmeraldum Rolston

Manchas negras nos ângulos póstero-laterais dos segmentos do conexivo cobrindo parte dos laterotergitos; borda do corpo laranja-avermelhada .....

A. (C.) istum Rolston

17(15). Margens ântero-laterais do pronoto com ampla depressão submarginal 
A. (C.) napaeum (Stål)

Margens ântero-laterais do pronoto destituídas de depressão submarginal, curvatura do disco do pronoto continuando suave e uniformemente em direção as margens ântero-laterais ........................... A. (C.) difficile (Stål)

18(3). Ápices ou pouco mais dos fêmures negros, pelo menos, na superfície dorsal; antenas negras ............................................................................. 19

Ápices dos fêmures verdes, amarelos ou vermelhos; antenas total ou predominantemente verdes 22

19(18). Mácula negra larga no dorso do hemiélitro incluindo a parte distal do cório e membrana .................................................. . (C.) panamensis (Distant)

Dorso destituído de mácula ou, se presentes, no pronoto e base do escutelo 20

20(19). Margens ântero-laterais do pronoto e margem lateral da base do cório amplamente bordeadas de amarelo; freqüentemente com uma faixa mediana amarela no pronoto e/ou escutelo e, muitas vezes, as margens laterais e/ou ápice do escutelo amarelados

A. (C.) grave (Walker)

Margens ântero-laterais do pronoto com borda amarelada incompleta ou difusa, ou não bordeadas; escutelo e disco do pronoto imaculado ou com manchas negras

21(20). As cicatrizes do pronoto e uma ampla mancha subquadrada, nos ângulos basais do escutelo, negras ....................................... (C.) nigropictum (Breddin)

Disco do pronoto e escutelo imaculados ................ (C.) geniculatum (Dallas)

22(18). Pontuação dorsal esparsa, a maioria das pontuações separadas entre si por distância igual ao diâmetro do segundo segmento antenal

A. (C.) viridans (Stål)

Pontuação dorsal densa com distância entre os pontos menor que o diâmetro do segundo segmento antenal ............................................................ 23

23(22). Conexivo imaculado ou marcado de negro nos ângulos póstero-laterais dos segmentos limitados aos esternitos (RoLston, 1983, fig. 34) ................. 24

Manchas do conexivo, pelo menos nos segmentos basais, expandindo-se sobre os laterotergitos (RoLston, 1983, figs 33, 40)

24(23). Rostro terminando na altura das mesocoxas; margens ântero-laterais do pronoto fortemente convexas .............. (C.) pennsylvanicum (Palisot de Beauvois)

Rostro estendendo-se além das metacoxas; margens ântero-laterais do pronoto sub-retilíneas ou fracamente convexas .............................................. 25

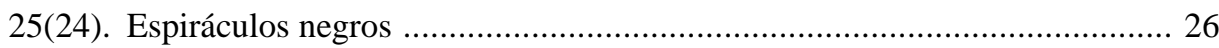

Espiráculos verdes, amarelos, castanhos ou vermelhos ............................. 30

26(25). A maior parte da pontuação dorsal escura, contrastante; calo em torno de cada espiráculo concolor, indistinto

Pontuação dorsal concolor; calos em torno de cada espiráculo, geralmente amarelados e contrastantes ................................................................ 27

27(26). Ângulos póstero-laterais dos esternitos com mancha negra conspícua ........ 29 Ângulos póstero-laterais dos esternitos com não mais do que diminutos espinhos negros 28

28(27). Os três segmentos basais das antenas destituídas de marcas negras; dentes apicais da projeção em aba do bordo ventral do pigóforo grandes (Rolston, 1983 fig. 84). A. (C.) aseadum Rolston 
Todos os segmentos antenais parcialmente negros; dentes apicais da projeção em aba do bordo ventral do pigóforo apenas um pouco maior que os demais (RoLston, 1983 fig. 91) A. (C.) ecuadorensis Rolston

29(27). Úmeros em ângulo obtuso; margens ântero-laterais do pronoto retilíneas ...... A. (C.) nigrodorsatum (Breddin) Úmeros amplamente arredondados; margens ântero-laterais do pronoto ligeiramente convexas ..................................... (C.) ubicum Rolston

30(25). Mancha negra no ângulo interno de cada cicatriz; algumas vezes também no ângulo externo A. (C.) laetum (Stål)

Cicatrizes imaculadas ................................................................ 31

31(30). Ruga ostiolar estendendo-se até a metade da distância entre o ostíolo e a margem lateral do tórax .................................................................. 32 Ruga ostiolar estendendo-se por aproximadamente 3/4 da distância entre o ostíolo e a margem lateral do tórax .................................................... 33

32(31). Cada espiráculo com pequeno calo marfim .................. (C.) simplicis Rolston Espiráculos destituídos de calo ..................................... (C.) euri Rolston

33(31). Cada espiráculo com pequeno calo marfim ....................................... 35

Espiráculos não acompanhados por calo de coloração distinta ................. 34

34(33). Margem costal na base do cório e margem apical do escutelo, alaranjadas ou amareladas ..................................................(C.) macdonaldi Rolston Margem costal do cório e ápice do escutelo verdes

A. (C.) wygodzinskyi Rolston

35(33). Projeção abdominal em forma de espinho projetando-se entre as metacoxas ..

A. (C.) monticola Rolston

Projeção abdominal em forma de tubérculo não ou apenas atingindo as metacoxas . 36

36(35). Bordo posterior dos gonocoxitos 8 em declive em direção ao meio; segmentos antenais 4 e 5 negros ou verdes distalmente ............ (C.) ubicum Rolston Bordo posterior dos gonocoxitos 8 transversal, arredondado no ângulo pósterolateral; segmentos antenais 4 e 5 castanhos distalmente

A. (C.) occasi Rolston

37(23). Base das tíbias vermelha ............................................................... 38

Base das tíbias verde ou amarela .................................................... 39

38(37). Ângulo costal do cório sobre o último segmento do conexivo

A. (C.) collis Rolston

Ângulo costal do cório sobre o penúltimo segmento do conexivo

39(37). Espiráculos negros ................................................................... 44

Espiráculos pálidos ............................................................... 40

40(39). Cada espiráculo sobre ou ao lado de um calo amarelado ......................... 41

Espiráculos sem calo; manchas amareladas às vezes presentes ................. 42

41(40). Cada espiráculo com calo na periferia .......................................... 60

Cada espiráculo contíguo com, mas não circundado por um calo .................

42(40). Ângulo costal do cório subagudo, atingindo o sexto esternito visível (RoLSTON, 1983, fig. 153) ................................. (C.) fuscopunctatum (Breddin) 
Ângulo costal do cório arredondado, atingindo o quinto esternito visível ... 43

43(42). Bordo posterior dos gonocoxitos 8 dotados de projeção póstero-lateral sobre a base dos laterotergitos 9 (RoLSTON, 1983, fig. 157); bordo ventral do pigóforo com ampla emarginação em forma de "v" (RoLston, 1983, fig. 159) .........

A. (C.) marginatum (P. \& B.)

Bordo posterior dos gonocoxitos 8 fortemente convexo (Rolston, 1983, fig. 164); emarginaçã̃o do bordo ventral do pigóforo pouco profunda, com pequeno entalhe (Rolston, 1983, fig. 166) ………......... (C.) hilare (Say)

44(39). Mancha negra no ângulo basal do escutelo ................. (C.) brasicola Rolston Ângulos basais do escutelo imaculados ........................................................ 45

45(44). Tubérculo abdominal quase atingindo o limite anterior das metacoxas

A. (C.) teretis Rolston

Tubérculo abdominal apenas atingindo o limite posterior das metacoxas ... 46

46(45). Úmeros em ângulo obtuso; margens ântero-laterais do pronoto retas

A. (C.) nigrodorsatum (Breddin)

Úmeros arredondados; margens ântero-laterais do pronoto levemente convexas

A. (C.) ubicum Rolston

47(3). Segmentos do conexivo, anterior e posteriormente, bordeados de negro (figs 1, $2,4)$ 48

Segmentos do conexivo bordeados de negro somente na margem posterior 52

48(47). Parte ou todo o fêmur com uma banda pré-apical negra

A. (C.) musivum (Berg)

Fêmur com banda negra apical ou ausente

49(48). Margens ântero-laterais do pronoto largamente bordeadas de negro próximo ao úmero e amarelas anteriormente A. (C.) rogenhoferi (Stål) Margens ântero-laterais do pronoto inteiramente bordeadas de vermelho ou amarelo 50

50(49). Suturas e pseudo-suturas do ventre abdominal contrastantes, negras A. (C.) erythrocnemis (Berg)

Suturas e pseudo-suturas do ventre abdominal concolor com o restante do ventre

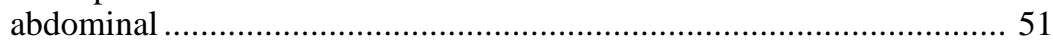

51(50). Cada espiráculo com calo amarelado .................................................... 63

Espiráculos sem calo .............................................. A. (C.) runaspis (Dallas)

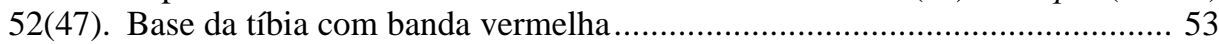

Tíbia sem banda basal ..................................................................... 54

53(52). Ângulo basal do escutelo com pequena mácula negra; espiráculos e calos dos espiráculos negros ..................................................... (C.) collis Rolston

Ângulo basal do escutelo imaculado; espiráculos vermelhos; calo do espiráculo amarelado ................................................. . (C.) montivagum (Distant)

54(52). Espiráculos negros .................................................................................... 55

Espiráculos pálidos; apenas o peritrema do espiráculo às vezes com estreito

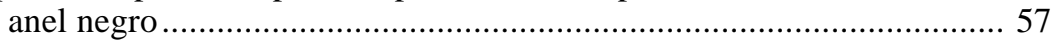

55(54). Tubérculo abdominal pronunciado; mancha negra usualmente no ângulo basal do escutelo e no ângulo interno das cicatrizes ..................................... 56

Tubérculo abdominal rudimentar; pronoto e escutelo sem manchas negras .... A. (C.) plaumanni Rolston 
56(55). Disco anterior do pronoto transversalmente deprimido, formando concavidade rasa; margens ântero-laterais do pronoto levemente convexas

A. (C.) dallasi (Distant)

Disco do pronoto fracamente convexo anteriormente, áreas submarginais deprimidas ausentes; margens ântero-laterais quase retilíneas

A. (C.) bipunctulum (Stål)

57(54). Cada espiráculo sobre um distinto calo amarelado; máculas amareladas presentes ao longo da base do escutelo ...................................... . (C.) laetum (Stål)

Cada espiráculo sobre um calo não ou pouco diferenciado na cor; máculas amareladas raramente presentes na base do escutelo ............................ 58

58(57). Mancha negra nos ângulos basais do escutelo.........A. (C.) impicticorne (Stål) Ângulos basais do escutelo destituídos de mancha negra ............................ 59

59(58). Borda dorsal do corpo não diferenciando-se na cor ou inconspicuamente amareloclara; espinho abdominal alcançando o limite anterior dos metatrocanteres A. (C.) herbidum (Stål)

Borda dorsal do corpo vermelha; espinho abdominal alcançando o limite posterior das metacoxas A. (C.) pengue Rolston

60(41). Cicatrizes do conexivo com mancha negra no ângulo interno e algumas vezes no ângulo lateral A. (C.) laetum (Stål)

Cicatrizes imaculadas ......................................... (C.) apicicorne (Spinola)

61(11). Segmentos do conexivo com pequena mancha negra no ângulo póstero-lateral; cicatrizes imaculadas ......................................... A. (C.) obstinatum (Stål) Segmentos do conexivo com mancha larga, negra, nos ângulos ântero- e pósterolaterais (fig. 2); cicatrizes com mácula negra no ângulo interno e, ocasionalmente, no ângulo externo ........................ (C.) panizzii sp. nov.

62(26). Margens ântero-laterais do pronoto levemente convexas; ângulos basais do escutelo sem fóveas, imaculados; rostro terminando entre as metacoxas ...

A. (C.) pecosum Rolston

Margem ântero-laterais do pronoto sub-retilíneas; ângulos basais do escutelo com pequenas fóveas castanho-claras (fig. 1); rostro ultrapassando o bordo anterior do III urosternito.

A. (C.) immaculatum sp. nov.

63(51). Cada espiráculo com calo amarelado; ângulos umerais arredondados ......... 64 Cada espiráculo com calo concolor, esverdeado; ângulos umerais subtriangulares (fig. 4) A. (C.) rideri sp. nov.

64(63). Espinho abdominal ultrapassando a linha posterior das metacoxas; ângulos umerais arredondados (fig. 3) .................... (C.) pontagrossensis sp. nov. Espinho abdominal não ultrapassando a linha posterior das metacoxas; ângulos umerais subtriangulares .............................. $(C$.) montivagum (Distant)

\section{Acrosternum (Chinavia) immaculatum sp. nov.}

(Figs. 1, 5-7,14-16, 23)

Etimologia. Nome alusivo à ausência de manchas negras no conexivo.

Superfície dorsal verde-oliva; ventralmente verde-oliva a alaranjada nos esternos torácicos e linha mediana do abdome. Margens laterais das jugas, do pronoto e terço 
basal do cório bordeados por uma faixa larga laranja-avermelhada, que se estende até a superfície ventral. Pontuações densas na superfície dorsal, castanhas a enegrecidas; pontuações na região ventral, finas, concolores a enegrecidas. Pernas esverdeadas; terço apical das tíbias e tarsos laranja-avermelhados (fig. 1).

Macho. Cabeça levemente mais larga que longa. Pontuações castanho-claras densamente distribuídas por toda a superfície. Jugas com as margens laterais suavemente sinuosas, subparalelas e convergentes apicalmente igualando-se ao clípeo em comprimento. Largura dos olhos com $1 / 4$ da distância interocular. Olhos enegrecidos. Ocelos negros. Segmentos antenais verde-escuros. Segmentos antenais II e III subiguais em comprimento; III segmento menor que o IV; V segmento antenal pouco menor que o IV. Superfície ventral da cabeça alaranjada, com finas pontuações concolores; pequena mancha linear negra na base do tubérculo antenífero. Rostro ultrapassando o limite anterior do III segmento abdominal, alaranjado, ápice do último segmento enegrecido. Pronoto aproximadamente três vezes mais largo que longo; pontuações castanho-claras, mais grosseiras que na cabeça, densamente distribuídas por toda a superfície. Margens ântero-laterais sub-retilíneas. Ângulos umerais agudos. Cicatrizes concolores e imaculadas. Coloração do escutelo como a do pronoto. Pequenas fóveas castanhoclaras nos ângulos basais. Hemiélitros com pontuações castanho-escuras densamente distribuídas. Ângulos póstero-laterais do cório arredondados, atingindo o limite posterior do 6o segmento do conexivo. Sutura da membrana sub-retilínea. Membranas translúcidas, levemente escurecidas próximo à margem interna da sutura. Pontuações da superfície ventral do tórax finas e irregularmente distribuídas, concolores a enegrecidas. Placa metasternal alaranjada. Ventralmente, uma linha verde-escura delimitando o pronoto da propleura. Tíbias dorsalmente sulcadas. Conexivo exposto com os ângulos póstero-laterais pouco pronunciados, imaculados, alaranjados a levemente avermelhados nas margens laterais; pontuações concolores, finas e densas. Superfície ventral do abdome com pontuações finas e concolores. Espinho do III segmento abdominal em tubérculo, de ponta romba, não ultrapassando o limite anterior do III segmento abdominal. Margens laterais do abdome e ângulos póstero-laterais de cada segmento alaranjados. Espiráculos negros.

Medidas. Comprimento total 11,25 (11,08-11,42); comprimento da cabeça 1,84 , largura 2,60 (2,52-2,68); comprimento adiante dos olhos $0,96(0,88-1,04)$; distância interocular $0,75(0,67-0,84)$; comprimento dos segmentos antenais I 0,49; II 1,06; III 1,23 ; IV 1,80; V 1,72; comprimento do pronoto 2,43 (2,35-2,52), largura 7,22; comprimento do escutelo 4,56, largura 4,08 $(4,00-4,16)$; largura do abdome $6,80(6,72-$ 6,88); comprimento do cório 6,52 (6,48-6,56).

Genitália. Pigóforo subtrapezoidal; ângulos póstero-laterais desenvolvidos e fortemente agudos; taça genital moderadamente escavada. Bordo dorsal (bd) côncavo nos terços laterais (fig. 5). Bordo ventral (bv) sinuoso e fortemente escavado medianamente em "V"; projetado dorsalmente em aba com a margem externa com uma série de dentes enegrecidos; ápice em nítido espinho enegrecido (fig. 6). Parâmeros (par) espatulados e longos (fig. 7). Segmento $\mathrm{X}(\mathrm{X})$ quadrangular com carena basal quase imperceptível, quase totalmente encoberta pelo bordo dorsal (fig. 5). Aparelho articular com placa basal (pb) simples e com um par de conectivos dorsais (cd). Conectivos dorsais alcançando a metade basal da phalloteca (ph) com um processus capitati (pc) pouco desenvolvido. Phalloteca tubular e levemente curvada dorsalmente. Base da 
phalloteca com um processo ovalado. Conjuntiva (cj) presente, reduzida com um par de processos digitiformes. Vésica (v) tubular, pouco desenvolvida, visível em vista dorsal. Membramblase (m) arredondada e visível em vista dorsal (figs 14-16).

Fêmea semelhante ao macho. Medidas. Comprimento total 11,59; comprimento da cabeça 2,01, largura 2,68; comprimento adiante dos olhos 0,72 ; distância interocular 0,84; comprimento dos segmentos antenais I 0,65 ; II 1,23; III 1,39; IV 1,88; V 1,80; comprimento do pronoto 2,52 , largura 7,39 ; comprimento do escutelo 4,24 , largura 4,16; largura do abdome 7,05; comprimento do cório 6,16.

Genitália. Bordo posterior do VII segmento abdominal côncavo na área que recobre a base dos gonocoxitos 8 (gc8), estes arredondados. Bordos suturais justapostos em quase toda a sua extensão, divergentes no ápice e na base; bordos posteriores subretilíneos. Laterotergitos 8 (la8) subtriangulares; bordo posterior com uma minúscula projeção. Laterotergitos 9 (la9) espatulares, não ultrapassando a banda que une dorsalmente os laterotergitos 8 . Pequena projeção de ponta romba junto ao bordo posterior das gonapófises 9 (g9) avançando sobre os gonocoxitos 9 (gc9). (fig. 23).

Material-tipo. Holótipo ơ', BRASIL, Mato Grosso, Utiariti, Rio Papagaio, 7.VIII.1961, K. Lenko col. (UFRG). Parátipos: Pará, Cachimbo,, , VI.1962, Alvarenga \& Oliveira col. (DZUP); Minas Gerais, Serra do Cipó, Jaboticatubas, O', 20.V.1973, Mountouchet col. (UFRG).

Diagnose. A. (C.) immaculatum caracteriza-se por apresentar o corpo marginado de laranja-avermelhado, com conexivo imaculado e terço das tíbias e tarsos laranjaavermelhados, além do espiráculo robusto não acompanhado por calo e espinho abdominal obsoleto. Diferencia-se de $A$. (C.) pecosum Rolston, 1983 pela pontuação dorsal densa e fina, castanha a enegrecida; pelas margens ântero-laterais do pronoto sub-retilíneas e pela presença de fóveas nos ângulos basais do escutelo. Em $A$. (C.) pecosum os fêmures são totalmente esverdeados e o corpo é marginado de amarelo; margens ântero-laterais levemente convexas; pontuação dorsal esverdeada, ocasionalmente negras e moderadamente densas.

\section{Acrosternum (Chinavia) panizzii sp. nov.}

(Figs. 2, 8-10, 17-19, 24, 27 )

Etimologia. Nome em homenagem ao Dr. A. R. Panizzi, do CNPS pelas importantes contribuições aos estudos de ecologia nutricional de heterópteros.

Superfície dorsal verde-musgo; ventralmente verde-claro. Pontuações densas na superfície dorsal; concolores a verde-escuras. Ventralmente com pontuações finas e concolores. Margens laterais das jugas, pronoto e terço basal do cório finamente bordeados por uma faixa negra e, outra mais interna, amarelo-pálida. Pernas esverdeadas; tíbias e tarsos ferrugíneos (fig. 2).

Macho. Cabeça levemente mais larga que longa. Pontuações concolores densamente distribuídas por toda a superfície. Jugas com margens laterais levemente sinuosas e convergentes apicalmente, igualando-se ao clípeo em comprimento. Largura dos olhos com $1 / 4$ da distância interocular. Olhos e ocelos negros. Segmentos antenais verde-claros; ápice dos segmentos I, II e III e base do IV com estreito anel ferrugíneo. Comprimento dos segmentos antenais aumentando progressivamente do I ao V. Superfície ventral da cabeça com pontuações concolores, densamente distribuídas e com pequena mancha linear negra na base do tubérculo antenífero. Rostro ultrapassando o limite anterior das 
metacoxas; coloração verde com ápice do último segmento enegrecido. Pronoto aproximadamente três vezes mais largo que longo. Pontuações concolores a verde-escuras, densas e uniformes, levemente mais grosseiras que as da cabeça, com exceção do terço anterior onde as pontuações são levemente menores. Margens ântero-laterais sutilmente convexas. Ângulos umerais fortemente convexos. Cicatrizes concolores com 1+1 máculas negras nos ângulos basais internos das cicatrizes. Em alguns exemplares, ocasionalmente, $1+1$ no ângulo basal externo. Escutelo com pontuações concolores a verde-escuras, densamente distribuídas; na base, pequenas áreas subcalosas amarelo-pálidas; pequenas fóveas negras nos ângulos basais. Hemiélitros com pontuações verde-escuras. Ângulos póstero-laterais do cório subtruncados, ultrapassando o meio do 6 o segmento do conexivo. Pequenas áreas subcalosas amarelo-pálidas. Membranas translúcidas; pequenas manchas castanhas próximas à base das nervuras e mais claras junto ao ápice do clavo. Sutura da membrana levemente convexa. Pontuações da superfície ventral do tórax finas e irregularmente distribuídas, concolores a castanho-claras, principalmente junto às coxas. Placa metasternal castanho-clara. Tibias dorsalmente sulcadas. Conexivo com apenas a margem externa exposta, ou não exposta. Coloração verde-claro com faixa uniforme, alaranjada, nas margens laterais. Pontuações concolores. Ângulos ântero e póstero-laterais enegrecidos e pouco pronunciados. Superfície ventral do abdome com pontuações finas concolores. Espinho do III segmento abdominal cônico e alongado, de ponta romba, ultrapassando a linha posterior das mesocoxas. Espiráculos negros. Ângulos pósterolaterais de cada segmento abdominal de coloração negra; margem lateral externa levemente pálida.

Medidas. Comprimento total 11,59 (10,92-12,60); comprimento da cabeça 1,57 (1,47-1,72), largura 2,80 (2,70-2,87); comprimento adiante dos olhos $0,83(0,73-090)$; distância interocular 1,67 (1,64-1,80); comprimento dos segmentos antenais I 0,44 (0,41$0,49)$; II $0,96(0,90-0,98)$; III 1,16 (1,06-1,23); IV 1,64; comprimento do pronoto 2,60 $(2,37-2,70)$, largura 7,44 (7,21-7,70); comprimento do escutelo 4,83 (4,59-5,08), largura 4,69 (4,51-4,92); largura do abdome 7,70 (7,38-7,87); comprimento do cório 7,16 (6,64$7,45)$.

Genitália. Pigóforo subtriangular, apresentando um suave estreitamento em direção à base; ângulos póstero-laterais bem desenvolvidos com ápice arredondado; taça genital fortemente escavada. Bordo dorsal fortemente côncavo lateralmente ao segmento X (fig. 8). Bordo ventral sinuoso e moderadamente escavado medianamente em "V", projetado dorsalmente em forma de aba subtriangular com dente mediano na margem externa; ápice em longo espinho (fig. 9). Parâmeros curtos, voltados para o segmento $\mathrm{X}$, com cabeça arredondada no ápice e, na base, pequena projeção digitiforme (fig. 10). Segmento $\mathrm{X}$ ovalado, com carena no terço basal, nitidamente visível em vista dorsal (fig. 8). Aparelho articular com placa basal simples com um par de conectivos dorsais e um par de conectivos ventrais. Conectivos dorsais alcançando o terço basal da phalloteca com processus capitati longo e bem desenvolvido. Conectivos ventrais em braços alongados. Phalloteca tubular, levemente curvada dorsalmente, com ápice levemente escavado medianamente. Conjuntiva presente, reduzida com um par de processos truncados. Vésica tubular, pouco desenvolvida, visível em vista dorsal e ventral. Membramblase arredondada (figs 17-19).

Fêmea semelhante ao macho. Medidas. Comprimento total 13,30 (12,93-13,60); comprimento da cabeça $1,72(1,56-1,88)$, largura $3,13(3,03-3,28)$; comprimento adiante 
dos olhos 0,92 (0,90-0,98); distância interocular 1,82 (1,80-1,88); comprimento dos artículos antenais I 0,59 (0,49-0,65); II 0,98 (0,90-1,06); III 1,36 (1,31-1,39); IV 1,80 $(1,72-1,88)$; comprimento do pronoto 3,07 (2,87-3,28), largura 8,48 (8,20-8,77); comprimento do escutelo 5,82 $(5,65-6,15)$, largura 5,45 $(5,16-5,74)$; largura do abdome 8,77 (8,44-9,02); comprimento do cório 8,34 (8,03-8,52).

Genitália. Bordo posterior do VII segmento abdominal côncavo na área que recobre a base dos gonocoxitos 8. Bordos suturais dos gonocoxitos 8 justapostos a ligeiramente divergentes no ápice e na base. Disco dos gonocoxitos 8 intumescidos; bordo posterior convexo. Laterotergitos 8 subtriangulares; margem posterior com minúscula projeção enegrecida. Laterotergitos 9 ultrapassando sutilmente a banda que une dorsalmente os laterotergitos 8. Pequena projeção de ponta romba junto ao bordo posterior dos gonapófises 9 e avançando sobre os gonocoxitos 9. Segmento X quadrangular (fig. 24). Espessamentos secundários das gonapófises 9 (esg9) amplas, subquadrangulares. Chitinelipsen (ch) irregularmente ovaladas. Orificium receptaculi (or) piriforme. Espessamento da íntima vaginal (eiv) subcônico. Ductus receptaculi (dr) anterior (dra) e posterior (drp) à área vesicular estreito e longo, pouco menor que o ductus na área vesicular; região anterior à área vesicular quase quatro vezes mais longa que a posterior e com diâmetro levemente maior. Pars intermedialis (pi) com diâmetro menor que o comprimento, cilíndrica, mais estreita que a capsula seminalis (cs); esta, esférica, com dois dentes contorcidos, de comprimento aproximadamente uma e meia vez ao da capsula seminalis e pars intermedialis juntas. Cristas anular anterior (caa) e posterior (cap) conspícuas; crista anular anterior voltada em direção ao ductus receptaculi (fig. 27).

Material-tipo. Holótipo ơ', BRASIL, Paraná, Curitiba, 17.IV.1975, A. R. Panizzi col., em Passiflora sp. (DZUP). Parátipos: $4 \sigma^{\circ}, 4$, idem dados do holótipo (o, , UFRG; $3 \sigma^{\circ}, 3$, CNPS).

Planta hospedeira. Passiflora sp. (Passifloraceae) (maracujá).

Diagnose. A. (C.) panizzii apresenta a cabeça, pronoto e terço basal do cório uniformemente esverdeados; espinho abdominal alcançando as mesocoxas; 1+1 manchas negras presentes nos ângulos basais externos das cicatrizes, ocasionalmente também presentes nos ângulos internos. Diferencia-se de $A$. (C.) obstinatum (Stål, 1860) pela presença de pequenas fóveas negras nos ângulos basais do escutelo e por apresentar uma larga mancha negra nos ângulos ântero e póstero-laterais de cada segmento do conexivo; em $A$. (C.) obstinatum apenas os ângulos póstero-laterais com diminutas manchas negras.

\section{Acrosternum (Chinavia) pontagrossensis sp. nov.}

(Figs. 3, 25, 28)

Etimologia. Nome alusivo à localidade-tipo.

Superfície dorsal e ventral verde-claro. Margens laterais das jugas, do pronoto e terço basal do cório finamente bordeados por uma faixa negra e, mais internamente, por uma faixa larga alaranjada. Pontuações densas na superfície dorsal, castanhas a negras; ventralmente pontuações mais finas, concolores a negras. Pernas verde-pálidas (fig. 3).

Macho semelhante à fêmea. Medidas. Comprimento total 11,42; comprimento cabeça 1,56, largura 2,54; comprimento adiante dos olhos 0,90; distância interocular 1,39; comprimento dos segmentos antenais I 0,49; II 0,82; III 1,23; IV 1,39; V 1,56; comprimento do pronoto 2,62, largura 6,72; comprimento do escutelo 4,59, largura 
4,51; largura do abdome 7,13; comprimento do cório 6,72.

Fêmea. Cabeça levemente mais larga que longa. Pontuações verde-escuras densamente distribuídas por toda a superfície. Em alguns exemplares, 1+1 manchas negras medianas na base da cabeça. Jugas com as margens laterais levemente sinuosas e convergentes apicalmente, igualando-se ao clípeo em comprimento. Nas margens do clípeo, uma mancha enegrecida irregular e de extensão variável. Largura dos olhos com 1/4 da distância interocular. Olhos castanho-escuros. Ocelos castanho-avermelhados. Segmentos antenais verde-oliváceos; I e II segmentos com anel apical de coloração ferrugínea. Terço apical do III, IV e V segmentos antenais totalmente enegrecidos. Comprimento dos segmentos antenais aumentando progressivamente do I ao V. Superfície ventral da cabeça com densa pontuação concolor e com mancha linear negra na base do tubérculo antenífero. Rostro alcançando o limite posterior das metacoxas, verde com ápice do último segmento enegrecido. Pronoto aproximadamente três vezes mais largo que longo. Pontuações castanhas a concolores, principalmente junto às margens ânterolaterais, estas sutilmente convexas. Ângulos umerais arredondados. Cicatrizes concolores; presença de 1+1 máculas negras na margem interna das cicatrizes, e ocasionalmente, 1+1 no ângulo basal externo, ou ausentes. Escutelo com pequenas áreas subcalosas amareladas. Pontuações castanhas a negras densamente distribuídas. Fóveas castanhoclaras nos ângulos basais. Hemiélitro com pontuações castanhas a negras. Ângulos póstero-laterais arredondados ultrapassando o limite entre o $6^{\circ}$ e o $7^{\circ}$ segmentos do conexivo. Pequenas áreas subcalosas amareladas, distribuídas irregularmente por toda a superfície. Membranas translúcidas com pequenas manchas castanhas próximas à base das nervuras. Sutura da membrana sub-retilínea. Pontuações da superfície ventral do tórax concolores a negras, principalmente junto às margens posteriores de cada segmento. Ventralmente, uma linha negra delimita o pronoto da propleura. Placa metasternal translúcida. Tíbias dorsalmente sulcadas. Conexivo exposto com os ângulos póstero-laterais pouco pronunciados; amarelo-pálido, com margens anterior e posterior de cada segmento com faixa negra larga e mais ou menos uniforme, margens laterais com faixa delicada amarelado mais intenso. Pontuações finas e concolores. Superfície ventral do abdome com pontuações finas e concolores. Espinho do III segmento abdominal cônico, de ponta romba, ultrapassando a linha posterior das metacoxas. Ângulos pósterolaterais de cada segmento abdominal de coloração negra; margens laterais externas com faixa alaranjada. Espiráculos negros com pequeno calo amarelado.

Medidas. Comprimento total 11,76 (11,60-11,93); comprimento da cabeça 1,88 (1,80-2,05), largura 2,84 (2,70-2,95); comprimento adiante dos olhos $0,92(0,90-0,98)$; distância interocular 1,68 (1,56-1,72); comprimento dos segmentos antenais I 0,49; II $0,98(0,90-1,06)$; III $1,16(1,06-1,31)$; IV 1,47 ; comprimento do pronoto 2,85 (2,54$3,11)$, largura 7,68 (6,97-8,20); comprimento do escutelo 5,33 (5,00-5,57), largura 5,02 (4,51-5,33); largura do abdome 7,93 (7,38-8,36); comprimento do cório 7,79 (7,21$8,20)$.

Genitália. Bordo posterior do VII segmento abdominal levemente côncavo na área que recobre a base dos gonocoxitos 8 . Bordos suturais dos gonocoxitos 8 justapostos a levemente divergentes na região apical e basal. Disco dos gonocoxitos 8 intumescidos; bordo posterior levemente convexo na metade externa e moderadamente côncavo na metade interna. Laterotergitos 8 subtriangulares com minúscula projeção; $2+2$ máculas negras nas margens posteriores. Laterotergitos 9 ultrapassando levemente a banda que 

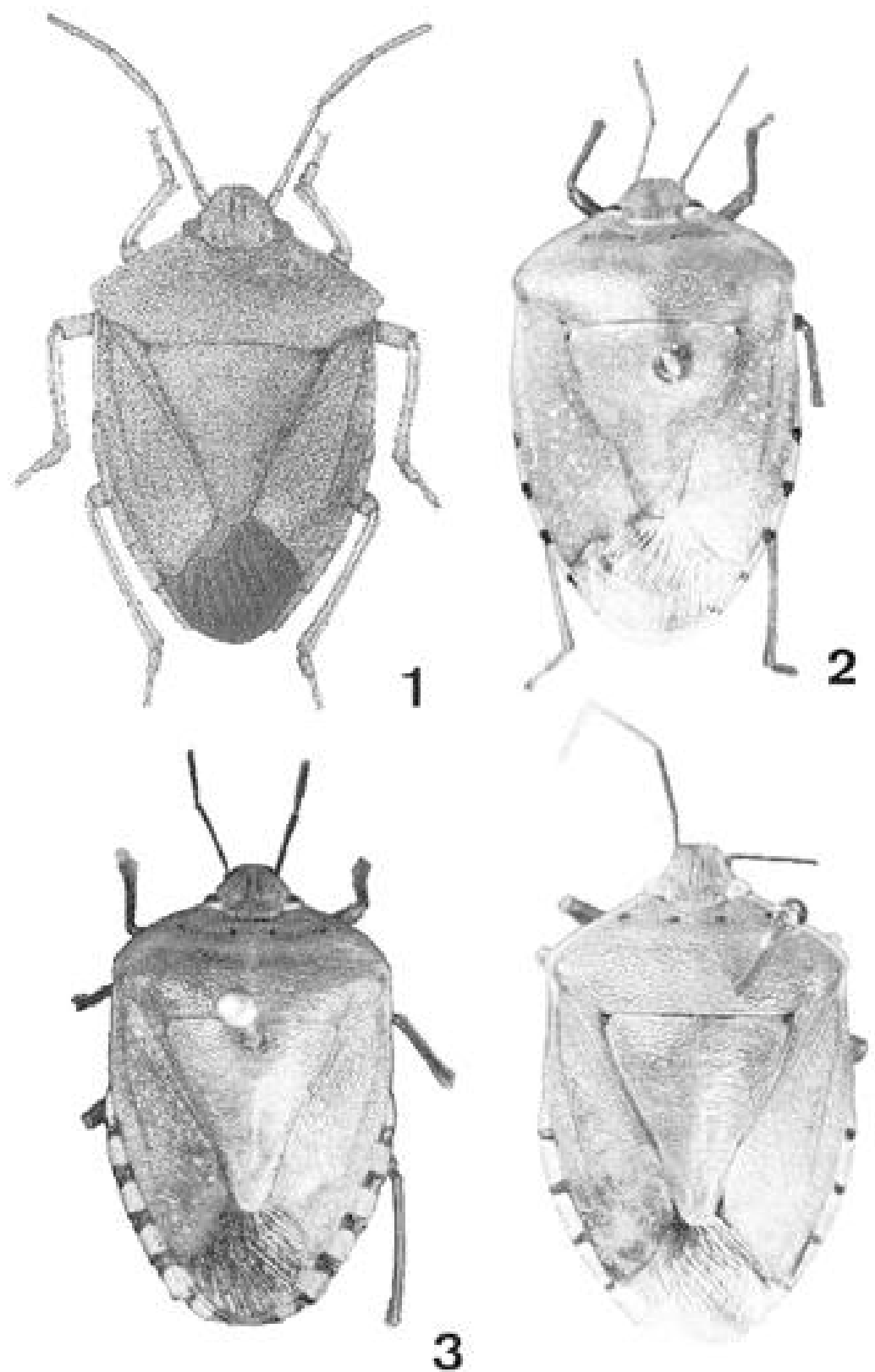

3

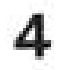

Figs. 1-4. 1, Acrosternum (Chinavia) immaculatum sp. nov. (ð); 2, A. (C.) panizzii sp. nov. (O’); 3, A. (C.)

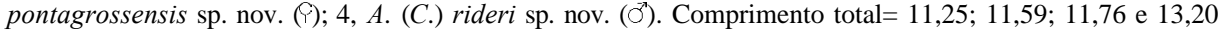
respectivamente. 
une dorsalmente os laterotergitos 8 . Pequena projeção de ponta romba junto ao bordo posterior das gonapófises 9 e projetando-se sobre os gonocoxitos 9. Segmento X quadrangular (fig. 25). Espessamentos secundários da gonapófise 9 amplos. Chitinellipsen estreitas e alongadas. Orificium receptaculi bilobado. Espessamento da íntima vaginal em formato subcônico. Ductus receptaculi antes e depois da área vesicular estreito e longo, pouco menor que o ductus na área vesicular; região anterior à área vesicular quase três vezes mais longa que a posterior, com diâmetros subiguais. Pars intermedialis com diâmetro menor que o comprimento, cilíndrica, mais estreita que a capsula seminalis; esta semiesférica, com dois dentes contorcidos de comprimento aproximadamente duas vezes maior do que a capsula seminalis e a pars intermedialis juntas. Cristas anulares anterior e posterior conspícuas; crista anular anterior voltada em direção ao ductus receptaculi (fig. 28).

Material-tipo. Holótipo ,, BRASIL, Paraná, Ponta Grossa, 22.IV.1975, em soja (DZUP). Parátipos: $\sigma^{\prime \prime}$, 1975, em soja (DZUP), 2 , idem dados do holótipo (UFRG, CNPS).

Planta hospedeira. Glycine max (L.) Merrill (Leguminosae) (soja).

Diagnose. A (C.) pontagrossensis tem o espinho abdominal ultrapassando a linha posterior das metacoxas e conexivo com mancha larga negra nas margens anterior e posterior de cada segmento. Difere de $A$. (C.) montivagum (Distant, 1890) pelas cicatrizes com 1+1 manchas negras nos ângulos internos e, ocasionalmente, $1+1$ nos ângulos basais externos, escutelo com fóveas nos ângulos basais. Em A. (C.) montivagum as cicatrizes e os ângulos basais do escutelo são imaculados.

\section{Acrosternum (Chinavia) rideri sp. nov.}

(Figs. 4, 11-13, 20-22, 26, 29)

Etimologia. Nome em homenagem ao Dr. D. A. Rider da University of North Dakota (EUA) pelas importantes contribuições dadas aos estudos dos heterópteros.

Superficie dorsal verde-oliva a verde-amarelada; ventralmente verde-clara. Margens laterais das jugas, do pronoto e terço basal do cório largamente bordeados por uma faixa vermelho-alaranjada que se estende até a superfície ventral. Pernas verdeclaras com anéis apical e basal das tíbias e tarsos ferrugíneos. Pontuações densas na superfície dorsal, concolores e negras. Superfície ventral com pontuações finas, concolores e negras (fig. 4).

Macho. Cabeça levemente mais larga que longa. Pontuações concolores densamente distribuídas por toda a superfície. Em alguns exemplares, 1+1 manchas negras medianas na base da cabeça. Jugas com as margens laterais levemente sinuosas, convergentes apicalmente, igualando-se ao clípeo em comprimento. Nas margens do clípeo, mancha enegrecida irregular e de extensão variável. Largura dos olhos com 1/3 da distância interocular. Olhos enegrecidos. Ocelos castanho-avermelhados. Segmentos antenais II, III e IV enegrecidos com anéis claros na base; I segmento esverdeado e V segmento marrom-claro a ocre. Comprimento dos segmentos antenais aumentando progressivamente do I ao IV; V segmento antenal pouco menor que o IV. Superfície ventral da cabeça verde-amarelada com pontuações concolores irregularmente distribuídas e com uma pequena mancha linear negra localizada na base do tubérculo antenífero. Rostro alcançando o limite posterior das metacoxas, amarelo-pálido, com o ápice do último segmento enegrecido. Pronoto aproximadamente três vezes mais largo 

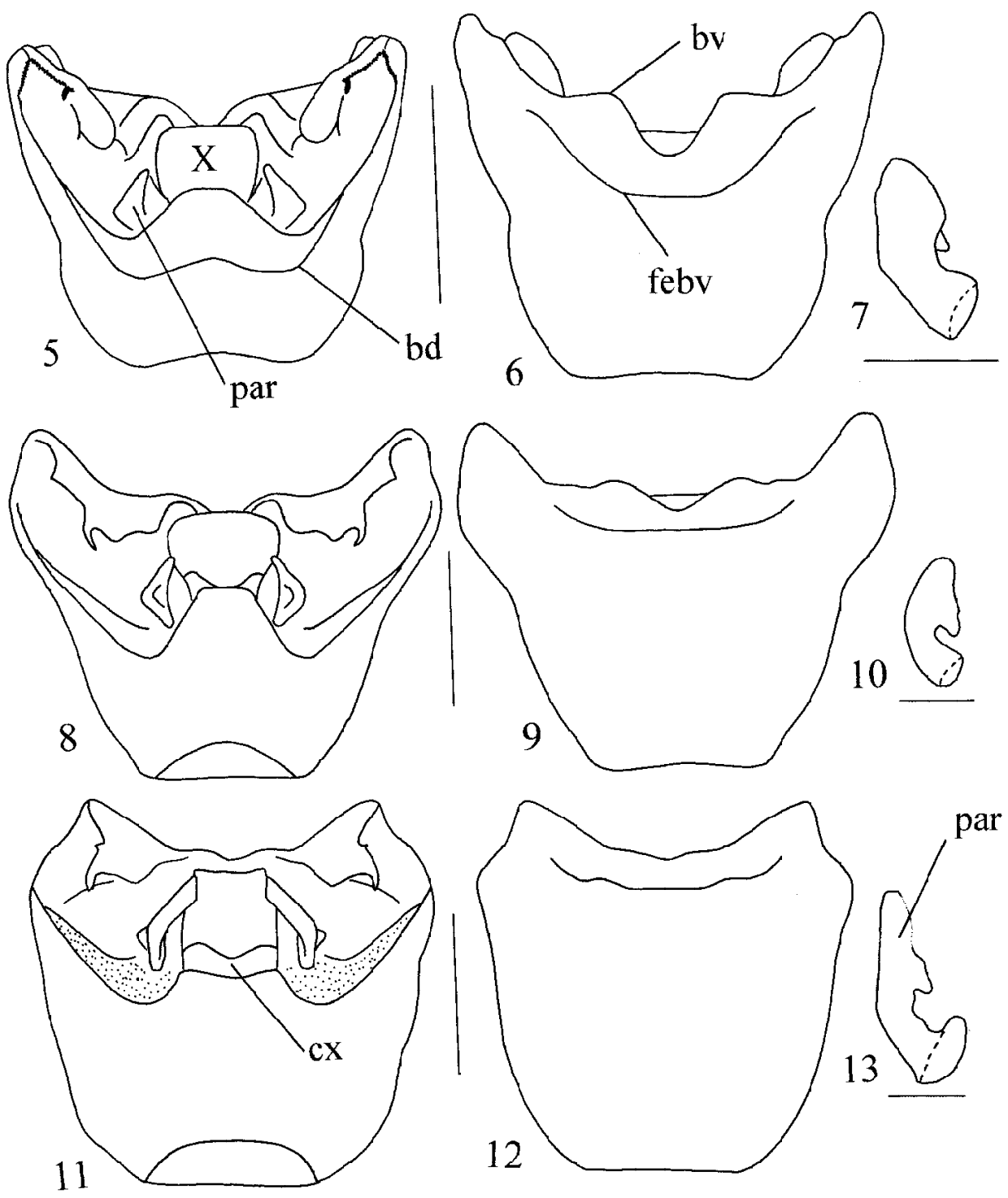

Figs. 5-13. Pigóforo, vista dorsal e ventral e parâmero esquerdo respectivamente. 5-7, Acrosternum (Chinavia) immaculatum sp. nov.; 8-10, A. (C.) panizzii sp. nov.; 11-13, A. (C.) rideri sp.nov. (bd, bordo dorsal; bv, bordo ventral; cx, carena do segmento X; febv, folheto externo do bordo ventral; par, parâmero; X, segmento X). Figs. 5, $6,8,9,11,12$ : barras, $1 \mathrm{~mm}$; figs. $7,10,13$ : barras, $0,5 \mathrm{~mm}$. 
que longo. Pontuações enegrecidas mais grosseiras que na cabeça, densamente distribuídas por toda a superfície, com exceção do terço anterior onde as pontuações são menores. Entre as pontuações, inúmeras áreas subcalosas amareladas. Margens ântero-laterais subretilíneas. Ângulos umerais subtriangulares. Cicatrizes concolores, com $2+2$ máculas negras aproximadamente circulares situadas no ângulo basal externo e ângulo interno. Escutelo com pequenas áreas subcalosas amareladas. Coloração como no pronoto, exceto no extremo apical vermelho-alaranjado com fina pontuação concolor. Pequenas fóveas negras nos ângulos basais. Hemiélitros com pontuações enegrecidas densamente distribuídas. Ângulos póstero-laterais do cório subtruncados atingindo o ápice do 60 segmento do conexivo. Sutura da membrana levemente convexa. Membranas translúcidas e enegrecidas na base junto ao ápice do clavo. Pontuações da superfície ventral do tórax finas e irregularmente distribuídas, concolores a enegrecidas, principalmente junto às margens posteriores de cada segmento. Uma linha negra delimita o pronoto ventral da propleura; $1+1$ pequena mancha negra no epímero da meso- e metapleura. Placa metasternal vermelho-alaranjada. Tíbias dorsalmente sulcadas. Conexivo exposto com os ângulos póstero-laterais pouco pronunciados. Pontuações concolores. Coloração vermelhoalaranjada, com faixas negras mais espessas internamente nas margens anterior e posterior de cada segmento do conexivo. Superfície ventral do abdome com pontuações finas concolores. Espinho do III segmento abdominal cônico e curto, de ponta romba, não ultrapassando a linha posterior das metacoxas. Ângulos póstero-laterais de cada segmento abdominal negros; margem lateral externa com pequenas manchas semi-circulares amareladas. Espiráculos negros com pequeno calo esbranquiçado.

Medidas. Comprimento total 13,20 (11,42-14,11); comprimento da cabeça 1,86 (1,55-2,05), largura 3,05 (2,95-3,19); comprimento adiante dos olhos 0,97 $(0,82-1,06)$; distância interocular $1,73(1,55-1,88)$; comprimento dos segmentos antenais I $0,60(0,57-$ 0,65); II 1,16 (1,06-1,31); III 1,66 (1,56-1,88); IV 2,12 (2,05-2,29); V 1,98 (1,88-2,05); comprimento do pronoto $2,95(2,54-3,28)$, largura $8,25(7,46-9,26)$; comprimento do escutelo 5,51 (4,92-6,15), largura 5,19 (4,67-5,90); largura do abdome 8,30 (7,38-9,26); comprimento do cório 8,01 (7,38-8,94).

Genitália. Pigóforo subquadrangular. Ângulos póstero-laterais fortemente angulosos; taça genital moderadamente escavada, inteiramente recoberta por longos e densos pêlos. Bordo dorsal côncavo nos terços laterais (fig. 11). Bordo ventral sinuoso medianamente, projetado dorsalmente em forma de aba, subtriangular, com a margem externa denteada e enegrecida; ápice em nítido espinho (fig. 12). Parâmeros longos; cabeça do parâmero espatulada no ápice e, na base, com pequena projeção em dente (fig. 13). Ápice do parâmero direcionado dorsalmente (fig. 11). Segmento X quadrangular, com uma carena no terço basal, nitidamente visível em vista dorsal (fig. 11). Aparelho articular com placa basal simples e com um par de conectivos dorsais e um par de conectivos ventrais. Conectivos dorsais alcançando o terço basal da phalloteca e apresentam um processus capitati pouco desenvolvido, espatular com dois processos laterais delicados. Conectivos ventrais alongados e finos. Phalloteca tubular e levemente curvada dorsalmente. Base da phalloteca com processo ovalado. Conjuntiva presente e reduzida com um par de processos digitiformes. Vésica tubular, pouco desenvolvida, cerca de $1 / 4$ do comprimento da phalloteca, visível em vista dorsal e ventral. Membramblase arredondada e visível dorsalmente (figs 20-22).

Fêmea semelhante ao macho. Medidas. Comprimento total 14,08 (12,76-15,12); 

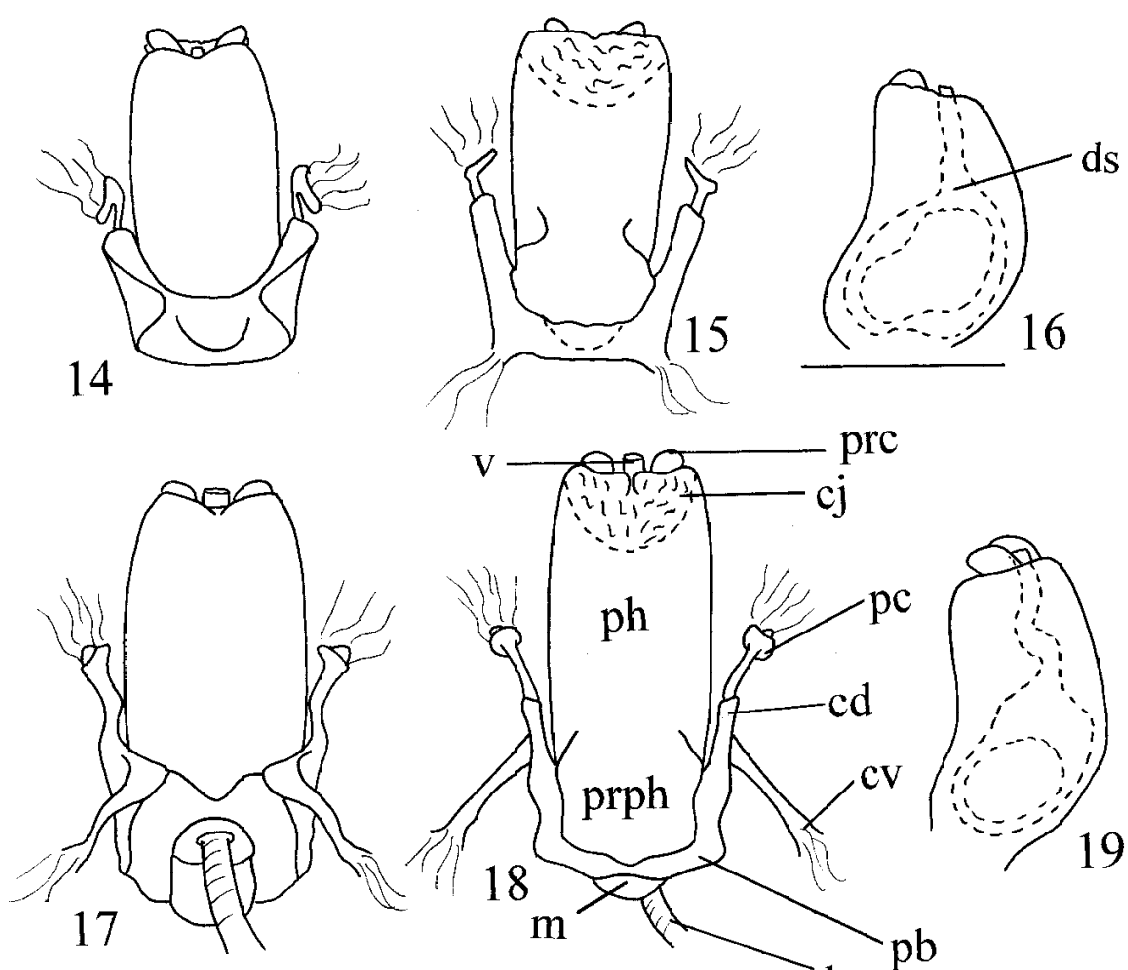

prc
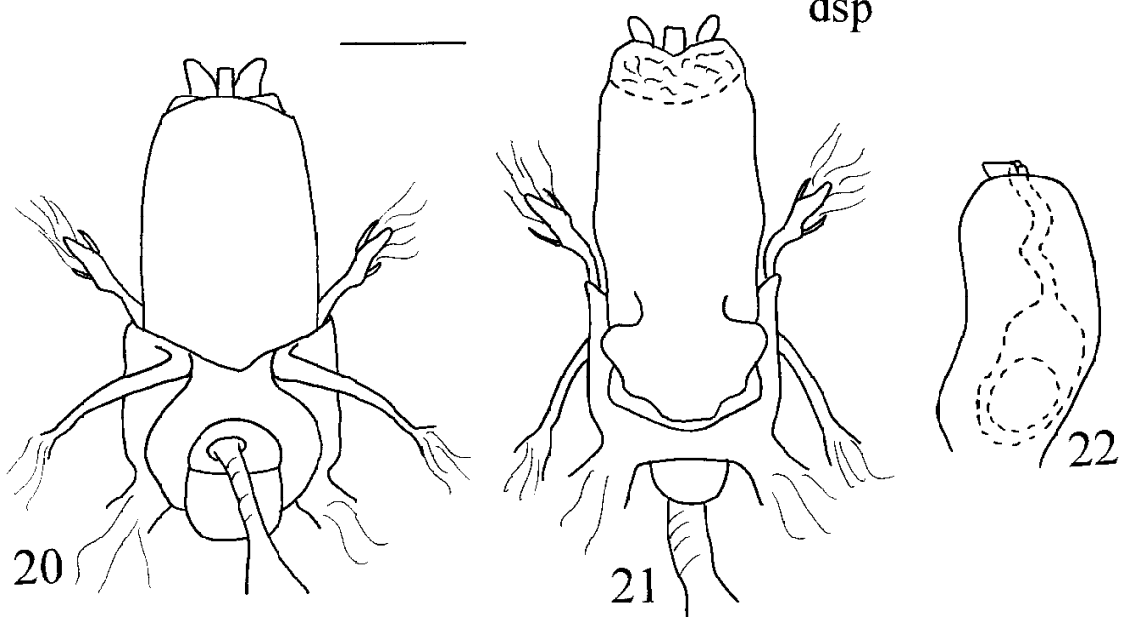

Figs 14-22. Phallus, vista dorsal, ventral e lateral respectivamente. 14-16, Acrosternum (Chinavia) immaculatum sp. nov.; 17-19, A. (C.) panizzii sp. nov.; 20-22, A. (C.) rideri sp. nov. (cd, conectivo dorsal; cj, conjuntiva; cv, conectivo ventral; ds, ductus seminis; dsp, ductus seminis proximalis; m, membramblase; pb, placa basal; ph, phalloteca; pc, processus capitati; prc, processo da conjuntiva; prph, processo da phalloteca; v, vésica). Barras, $0,5 \mathrm{~mm}$, figs $14-16 ; 17-22$ respectivamente na mesma escala. 


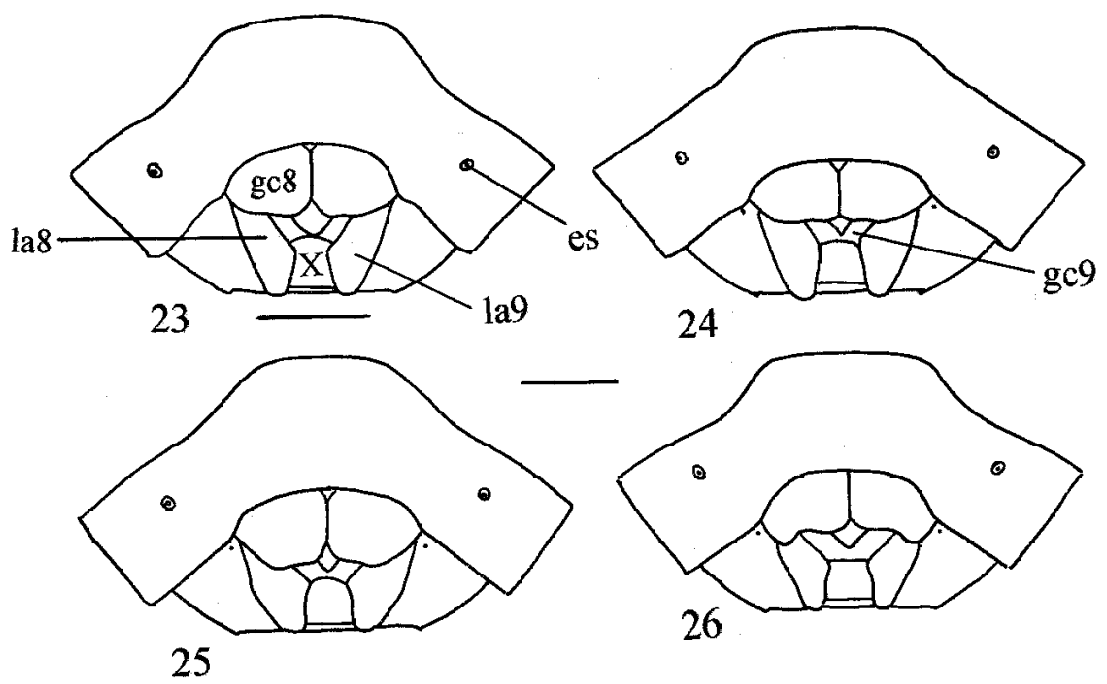

Figs 23-26. Placas genitais da fêmea, vista ventral. 23, Acrosternum (Chinavia) immaculatum sp. nov.; 24 , A. (C.) panizzii sp. nov.; 25, A. (C.) pontagrossensis sp. nov.; 26, A. (C.) rideri sp. nov. (es, espiráculo; gc8, gonocoxitos 8; gc9, gonocoxitos 9; la8, laterotergitos 8; la9, laterotergitos 9; VII, 7o segmento abdominal; X, segmento $\mathrm{X}$ ). Barras, $1 \mathrm{~mm}$, figs 24-26 na mesma escala.

comprimento da cabeça 1,94 (1,72-2,21), largura 3,11 (2,87-3,19); comprimento adiante dos olhos 1,02 (0,90-1,15); distância interocular 1,81 (1,64-1,96); comprimento dos segmentos antenais I 0,62 (0,49-0,82); II 1,23 (1,14-1,31); III 1,72 (1,55-2,05); IV 2,23 $(2,05-2,46) ;$ V 2,13 (2,05-2,21); comprimento do pronoto $3,12(2,87-3,36)$, largura 8,67 (7,62-9,43); comprimento do escutelo 5,77 (5,16-6,23), largura 5,52 (6,06-4,83); largura do abdome 8,73 (7,70-9,51); comprimento do cório 8,71 (7,38-9,43).

Genitália. Bordo posterior do VII segmento abdominal côncavo na área que recobre a base dos gonocoxitos 8 . Estes, mais longos que largos. Bordos suturais dos gonocoxitos 8 justapostos a ligeiramente divergentes nos extremos apical e basal. Bordo posterior dos gonocoxitos 8 convexo na metade externa, projetando-se sobre os laterotergitos 9 , cobrindo parcialmente a base destes; côncavo na metade interna. Laterotergitos 8 subtriangulares; bordo posterior com minúscula projeção. Laterotergitos 9 ultrapassando sutilmente a banda que une dorsalmente os laterotergitos 8 . Pequena projeção de ponta romba junto ao ápice das gonapófises 9 projetando-se sobre os gonocoxitos 9 . Segmento $\mathrm{X}$ quadrangular (fig. 26). Espessamentos secundários das gonapófises 9 amplos. Chitinellipsen irregularmente ovaladas. Orificium receptaculi arredondado. Espessamento da íntima vaginal subcônico. Ductus receptaculi antes e depois da área vesicular muito curto em relação ao comprimento do ductus na área vesicular; região do ductus receptaculi anterior à área vesicular quase três vezes mais longa e com quase o dobro do diâmetro que a região posterior à área vesicular. Pars intermedialis com diâmetro menor que o comprimento, cilíndrica, mais estreita que a capsula seminalis; esta, semiesférica, com dois dentes sub-retilíneos e voltados em direções opostas, bem mais longos do que a capsula seminalis e pars intermedialis juntas. Crista anular 

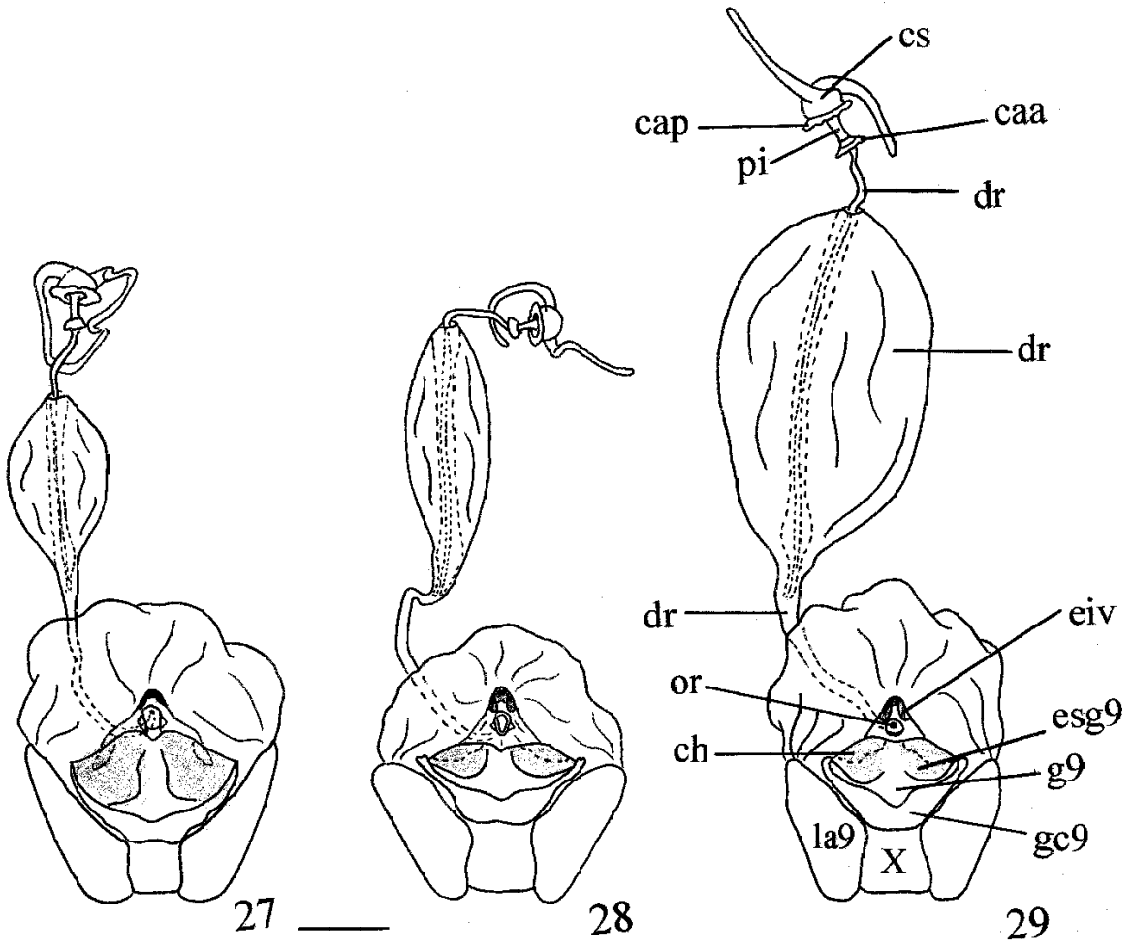

Figs 27-29. Vias ectodérmicas da fêmea, vista ventral. 27, Acrosternum (Chinavia) panizzii sp. nov.; 28, A. (C.) pontagrossensis sp. nov.; 29, A. (C.) rideri sp. nov. (caa, crista anular anterior; cap, crista anular posterior; ch, chitinellipsen; cs, capsula seminalis; dr, ductus receptaculi; eiv, espessamento da íntima vaginal; esg9, espessamento secundário das gonapófises 9; g9, gonapófises 9; gc9, gonocoxitos 9; la9, laterotergitos 9; or, orificium receptaculi; pi, pars intermedialis; $\mathrm{X}$, segmento $\mathrm{X}$ ). Barra, $1 \mathrm{~mm}$.

anterior voltada em direção ao ductus receptaculi; crista anular posterior conspícua (fig. 29).

Material-tipo. Holótipo ơ', BRASIL, Mato Grosso, Chapada dos Guimarães, 21.XI.1983 (DZUP). Parátipos: Amazonas, Estação Silvicultura do INPA, Y, 2.II.1976, Py Daniel Rapp col. (INPA); Mato Grosso, Cuiabá, on, 1963, M. Alvarenga col. (DZUP); Chapada dos Guimarães, 3 o, 3 (DARC); Distrito Federal, Brasília, O', 13.X.1969, J. M. \& B. O. Campbell col.(DARC); §, 10.XI.1978, H. M. Santos col., em Bauhinea sp. (UFRG); Y, XII.1971, V. Staviarski col. (MNRJ); ठ', UNB; , 06.VI.1979 (UFRG); Planaltina, ó, 27.VIII.1979, G. P. Santos col. (UFRG); Goiás, Jataí, Fazenda Nova Orlandia, 2 9, ơ, I.1964, Martin, Morgante \& Silva col. (UFRG); Minas Gerais, Paracatu, 2 o', VII.1960, Exp. Formosa col. (MNRJ); Sacramento, o', 26.III.1965, C. \& T. Elias col. (DZUP); Fazenda Unai, Y, 18.III.1978, J. G. Smith col., em soja (UFRG); Passos, o', IV.1964, C. Elias col. (UFRG); 9 , O.1961, C. Elias col. (DZUP); 2 9, III. 1961, C. Elias col. (UFRG).

Plantas hospedeiras. Glycine max (L.) Merrill (soja) e Bauhinea sp.

Diagnose. Em A. (C.) rideri o conexivo apresenta nas margens anterior e posterior de cada segmento, uma larga mancha negra que se torna mais espessa medianamente; ápice do escutelo amarelado; espiráculos negros acompanhados por calo concolor e espinho abdominal alcançando as metacoxas. Diferencia-se de $A$. (C.) montivagum pela presença de 2+2 máculas negras situadas nos ângulos basais externo e interno das 
cicatrizes e pelas pequenas fóveas negras nos ângulos basais do escutelo e de $A$. (C.) pontagrossensis pelos ângulos umerais subtriangulares, margens ântero-laterais do pronoto sub-retilíneas e segmentos antenais II, III e IV enegrecidos com anéis basais claros. de material.

Agradecimentos. Ao Dr. David A. Rider (DARC) e ao Dr. Antonio R. Panizzi (CNPS) pelo empréstimo

\section{REFERÊNCIAS BIBLIOGRÁFICAS}

DupuIs, C. 1970. Heteroptera. In: Tuxen, S. L. ed. Taxonomist's glossary of genitalia of Insects. Copenhagen, MunksGaard. p. 109-209.

FIEBER, F. X. 1860. Die Europäischen Hemiptera. Wien, Druck \& Verlag. 331 p.

Linnavouri, R. 1972. Studies on African Penatatomidae. Arq. Mus. Bocage, Lisboa 3(15): 415-434.

Orian, A. J. E. 1965. A new genus of Pentatomidae from Africa, Madagascar and Mauritius (Hemiptera). Proc. R. ent. Soc. Lond., (B), London, 34(3-4):25-29.

Rolston, L. H. 1983. A revision of the genus Acrosternum Fieber, subgenus Chinavia Orian in the Western Hemisphere (Hemiptera, Pentatomidae). JI N. Y. ent. Soc., New York, 91(2):97-176.

SILVA, A. G. D'; GonÇALVES, C. R. et al. 1968. Quarto catálogo dos insetos que vivem nas plantas do Brasil, seus parasitos e predadores. pt.2, v.1, Rio de Janeiro, Laboratório Central de Patologia Vegetal -MA. 622 p.

Vecchio, M. C. Del; Grazia, J. \& Hidelbrand, R. 1988. Estudo dos imaturos de Pentatomídeos que vivem sobre soja (Glycine max (L.) Merrill): V-Acrosternum bellum Rolston, 1983, com a descrição da genitália da fêmea. Anais. Soc. ent. Brasil, Porto Alegre, 17(2):467-482. 